\title{
A narrative review of stroke incidence, risk factors and treatment in Indigenous Peoples of the world
}

\author{
Angela Dos Santos ${ }^{1,2,3}$, Anna H. Balabanski ${ }^{2,3,4}$, Judith M. Katzenellenbogen ${ }^{5}$, Amanda G. Thrift ${ }^{6}$, Luke \\ Burchill ${ }^{1}$, Mark W. Parsons ${ }^{1,2,7,8}$ \\ ${ }^{1}$ Faculty of Medicine, Dentistry and Health Sciences, University of Melbourne, Melbourne, Victoria 3052, Australia. \\ ${ }^{2}$ Melbourne Brain Centre, University of Melbourne, Melbourne, Victoria 3052, Australia. \\ ${ }^{3}$ Department of Neurology, Alfred Health, Melbourne, Victoria 3004, Australia. \\ ${ }^{4}$ Department of Medicine, School of Clinical Sciences, Monash University, Clayton, Victoria 3800, Australia. \\ ${ }^{5}$ School of Population and Global Health, The University of Western Australia, Perth, Western Australia 6009, Australia. \\ ${ }^{6}$ Stroke and Ageing Research, Department of Medicine, School of Clinical Sciences at Monash Health, Monash University, \\ Clayton, Victoria 3800, Australia. \\ ${ }^{7}$ University of New South Wales, South Western Sydney Clinical School, Department of Neurology, Liverpool Hospital, Ingham \\ Institute for Applied Medical Research, Liverpool, Hospital, New South Wales 2170, Australia. \\ ${ }^{8}$ School of Medicine and Public Health, Faculty of Medicine, University of Newcastle, New South Wales 2308, Australia.
}

Correspondence to: Dr. Angela Dos Santos, Faculty of Medicine, Dentistry and Health Sciences, University of Melbourne, 300 Grattan St, Parkville, Victoria 3052, Australia. E-mail: adossantos@student.unimelb.edu.au

How to cite this article: Santos AD, Balabanski AH, Katzenellenbogen JM, Thrift AG, Burchill L, Parsons MW. A narrative review of stroke incidence, risk factors and treatment in Indigenous Peoples of the world. Vessel Plus 2021;5:21.

https://dx.doi.org/10.20517/2574-1209.2020.69

Received: 9 Nov 2020 First Decision: 4 Jan 2021 Revised: 6 Feb 2021 Accepted: 24 Mar 2021 Available online: 23 Apr 2021

Academic Editor: Aaron S. Dumont Copy Editor: Xi-Jun Chen Production Editor: Xi-Jun Chen

\begin{abstract}
Stroke is the second leading cause of death and the third greatest cause of disability worldwide. In some countries, stroke disproportionally affects Indigenous Peoples, with greater incidence and mortality at younger ages, higher rates of conventional cardiovascular risk factors and lower treatment rates. Worldwide there are 470 million Indigenous Peoples, residing in 90 countries. Analogous to the general health of all populations, the cause of stroke and its outcomes are the result of complex interactions between factors that act at societal, service, and individual levels. Colonisation, including the cultural and material losses associated with it, is a major indirect driver of disparities in lifestyle, biological and other risk factors for stroke in Indigenous Peoples. In addition, structural racism and the inability to access culturally safe education, employment and health care, further contribute to stroke health inequities for Indigenous Peoples globally. In this narrative review we provide an outline of stroke incidence rates, common risk factors for stroke, treatment rates with intravenous thrombolysis and endovascular clot retrieval in adult Indigenous populations in comparison to the non-Indigenous population of the same region. Our objective is to describe the differences that exist between the Indigenous and non-Indigenous populations with stroke in a particular region and discuss potential solutions that support a "strengths-based" approach driven by
\end{abstract}


Indigenous People.

Keywords: Stroke, Indigenous Peoples, first nations, incidence, risk factors, treatment, management

\section{INTRODUCTION}

It is estimated that 476 million Indigenous Peoples live in over 90 countries worldwide ${ }^{[1]}$. The World Health Organisation (WHO) defines Indigenous Peoples as "communities that live within, or are attached to, geographically distinct traditional habitats or ancestral territories, and who identify themselves as being part of a distinct cultural group, descended from groups present in the area before modern states were created and current borders were defined. Usually, they are considered the original inhabitants of their lands ("First Peoples"). They generally maintain cultural, economic, political and social identities separate from the mainstream or dominant society or culture in which they live ${ }^{[2]}$. There is great diversity between and within Indigenous Peoples around the world. However, Indigenous Peoples typically share more holistic concepts of health as well as the common experience of poorer health outcomes, particularly in relation to cardiovascular diseases (including stroke), when compared with their non-Indigenous counterparts ${ }^{[3]}$. These health inequities relate to the ongoing socio-economic, cultural and environmental consequences of colonisation and racism ${ }^{[3-5]}$. These health inequities exist not only in low- and middle-income countries, but also in high-income countries where the dominant society typically experience substantially higher quality of life and life expectancy ${ }^{[6]}$.

Stroke is the second leading cause of death and the third greatest cause of disability worldwide ${ }^{[7]}$. Seventy percent of those strokes and $87 \%$ of stroke-related deaths and disability-adjusted-life-years (DALYs) occur in low- and middle-income countries ${ }^{[8-10]}$. Within those low- and middle-income countries, where stroke typically affects patients at younger ages, there is typically a greater proportion of intracerebral haemorrhage (ICH) compared with ischaemic stroke (IS), and greater mortality rates ${ }^{[0]}$. These patterns of stroke incidence and mortality are also seen in Indigenous populations around the world, even within high-income countries $^{[11]}$.

In this narrative review we provide an outline of stroke incidence rates, common risk factors for stroke, treatment rates with intravenous thrombolysis and endovascular clot retrieval in adult Indigenous populations in comparison to the non-Indigenous population in the same region. This narrative review includes Indigenous Peoples where data have been published on the subject. We acknowledge that stroke has not been studied in all Indigenous groups; hence, we were unable to provide data on these Indigenous Peoples. Given the breadth of this topic, we will focus on Indigenous Peoples who represent a minority group within their country, many of whom share a history of colonisation. We will not draw direct comparisons between different Indigenous populations, due to inconsistencies in determining Indigenous status, study design, data collection and standardisation ${ }^{[12]}$.

Our objective is to understand the differences in stroke between Indigenous and non-Indigenous populations leading to a discussion on potential solutions for improving stroke-related health outcomes for Indigenous Peoples around the world. Specifically, we focused on peer-reviewed literature that discusses stroke incidence, cardiovascular risk factors and treatment with thrombolysis or endovascular clot retrieval in Indigenous populations in comparison to the non-Indigenous population in the same region. 


\section{METHODS}

Using narrative review methods ${ }^{[13]}$ we searched PubMed and performed manual searches of references from retrieved literature. Our PICO model was defined as: P: Indigenous Peoples, I: Stroke, C: Non-Indigenous Peoples, O: Incidence or prevalence, risk factors and treatment. Our Indigenous search terms were extensive and comprehensive in order to include all possible Indigenous groups worldwide. Papers were only included if they comprehensively assessed either incidence or prevalence, cardiovascular risk factors, or treatment of stroke in the Indigenous population of the specific region and made reference to the nonIndigenous Peoples in the same region.

\section{RESULTS}

\section{Incidence of stroke in Indigenous Peoples}

Indigenous populations typically experience greater rates of stroke incidence compared with the nonIndigenous population in the same region ${ }^{[11,14,15]}$. The reasons for this are multifactorial and differ between the different populations; however, many Indigenous populations share common health and socioeconomic disadvantages as described above $e^{[3,4]}$. Relatively few comparative data for certain regions have been published. There are many reasons for this, including that some Indigenous groups have expressed the wish not to be compared in this way to other population groups.

In Australia, the age-standardised incidence rate of stroke in Aboriginal and Torres Strait Islander (Indigenous) Australians has been reported to be significantly greater than that in the non-Indigenous population $^{[1,14-16]}$, with even greater disparities at younger ages ${ }^{[11]}$. In one study, comprising prospectively ascertained data, the incidence of all stroke subtypes in the Indigenous Australian population of South Australia aged $<55$ years was 3.5 -fold that of the non-Indigenous population ${ }^{[11]}$. In this study, the rate of ICH was especially high in this younger population, 16-fold greater than that in the non-Indigenous population of the same age ${ }^{[11]}$. In Aotearoa (New Zealand), the Māori population have experienced improvements in stroke incidence over the past three decades. However, these improvements have been of a lesser magnitude than New Zealanders of European descent ${ }^{[17]}$. In the Pacific Islands, stroke is one of the leading causes of death and disability; however, precise measurements of incidence in these regions are $\operatorname{sparse}^{[18]}$.

In Asia, few studies have specifically been undertaken to investigate the incidence of stroke in Indigenous Peoples. In one study, the age-standardised incidence rate of stroke in Lhasa, Tibet, was less in Indigenous Tibetan people than that in Han Chinese people ${ }^{[19]}$. However, in those with incident stroke, Tibetan patients had a greater proportion of ICH (47.9\%) than Han Chinese patients $(29.5 \%)^{[19]}$. Similarly, few data are available on the incidence of stroke in Indigenous Peoples of the Middle East. In one retrospective cohort study, the Ramadan month of fasting was associated with a significantly increased rate of hospitalisation for incident IS among the Indigenous Bedouin Arab people in southern Israel, when compared with the rest of the year, and when compared with non-Bedouin people during the month of Ramadan ${ }^{[20]}$. Furthermore, during the full (Ramadan and non-Ramadan) study period, Bedouin patients with incident IS were younger than non-Bedouin patients (66.9 years $v s .73 .1$ years, $P<0.001)^{[20]}$. In our search, we were unable to identify any peer-reviewed literature describing the incidence of stroke in Indigenous minorities of Africa.

In a single study in the Americas (excluding Hawaii), there was a greater incidence of stroke in American Indians and Alaska Natives than in White and Black Americans ${ }^{[2,22]}$. Overall, there were similar proportions of ischaemic and haemorrhagic stroke subtypes between these different groups. However, in younger age groups, there was a greater proportion of haemorrhagic stroke in American Indians ${ }^{[21]}$. Muller et al. ${ }^{[23]}$ recently pooled data from two cohort studies, and showed that the age-standardised incidence of stroke in 
American Indians was greater than in Whites and generally less than in Blacks, before adjusting for the presence of risk factors. Notably, they also found that post-stroke mortality was greater in American Indians than in Black or White Americans ${ }^{[23]}$. In a more recent study on the incidence of stroke in the Alaska Native population, Boden-Albala et al..$^{[24]}$ found that the overall annual age-standardised incidence of stroke was similar to that of the annual incidence estimates for United States Whites, and lower or similar to other ethnic minority groups in the United States. However, Alaskan Native people experienced greater rates of stroke than United States Whites in all age groups except among those aged 20-24 years, when using data from the Northeast Manhattan Study as a benchmark ${ }^{[25]}$. Furthermore, substantial geographic heterogeneity in incidence rates was noted. The incidence rates of stroke in Alaska Natives residing in the Northwestern Arctic region were significantly greater than in the Kodiak and Interior regions. Rates of stroke in Alaskan Natives were greater in men than in women, though women aged $>75$ years had greater rates of haemorrhagic stroke ${ }^{[24]}$. In Canada, the age-standardised prevalence of stroke was 2 -fold greater in Inuit adults in northern Canada than in the general Canadian population, with disparities most notable in those aged $<60$ years $^{[26]}$. Greater incidence rates of stroke have also been reported in the Métis Peoples of Canada, compared to others in the same region of Manitoba ${ }^{[27]}$. Few data have been published on the incidence of stroke in the Indigenous Peoples of South America ${ }^{[28]}$. Saposnik et al. ${ }^{[28]}$, in their systematic review of stroke in South America found relatively low incidence rates in the Indigenous population, but these studies comprised datasets from the 1980s to 1990s, and are likely to be outdated. In a 1-year follow-up of a cohort of 1514 individuals conducted among the Chiquitano tribe from the southern Amazonas region in Bolivia, the crude incidence of stroke was estimated to be 35 per $100,000^{[28]}$. Case numbers were small and agestandardised incidence rates were not available; these relatively low crude rate estimates may have been affected by selection bias as well as a younger age structure of this specific population, relative to the WHO World Standard Population ${ }^{[29]}$. There was no comparison with a non-Indigenous population in the same region $^{[30]}$.

In Europe and Russia, disparities in the incidence of stroke between the Indigenous and non-Indigenous populations are less clear. In Scandinavia, the incidence of stroke has been reported to be greater in the Sami population compared with that in the non-Sami population of the same Nordic regions ${ }^{[31,32]}$, with notable differences also reported between reindeer-herder and non-herder Sami people ${ }^{[32]}$. Sjölander et al. ${ }^{[32]}$ reported a greater incidence of stroke in the Sami population of Sweden overall, when compared with the non-Sami population. However, reindeer-herding Sami men had a significantly lower age-adjusted incidence of stroke, and reindeer-herding Sami women had a significantly greater incidence of stroke, when compared to the non-Sami population. In particular, subarachnoid haemorrhage was significantly greater in reindeer-herding Sami women than in non-Sami women with a standardised incidence ratio of 3.2. This disparity was seen to a lesser extent in reindeer-herding Sami men (standardised incidence ratio of 1.4), though with overlapping confidence intervals. Interestingly, reindeer-herding Sami women had a significantly lower incidence of myocardial infarction than non-Sami women ${ }^{[32]}$. In a study in Yakutia, Russia, a region which is home to a significant proportion of Indigenous Peoples (including Yakuts, Evenks, Evens, Dolgans, Yukagirs and Chukchi Peoples), there were no significant differences in the mean age of incident stroke ${ }^{[33]}$. Still, the proportion of haemorrhagic stroke was greater in the Indigenous patients (38\%) than in the Caucasian Russian patients with incident stroke $(20.2 \%, P<0.05)^{[32]}$.

\section{Risk factors for stroke in Indigenous Peoples}

The major traditional modifiable risk factors for stroke are similar to coronary heart disease and peripheral vascular disease. These include hypertension, hypercholesterolaemia and diabetes mellitus ${ }^{[34]}$. Lifestyle factors such as smoking, inadequate levels of physical activity, unhealthy diet and obesity ${ }^{\left[{ }^{[3]}\right.}$ are equally important and often trend higher in Indigenous Peoples ${ }^{[5,35-38]}$. Age is the single most important risk factor for stroke ${ }^{[39]}$, yet Indigenous patients worldwide experience stroke approximately a decade younger than 
their non-Indigenous counterparts ${ }^{[11,15,36,40-44]}$. Why stroke occurs at a younger age in Indigenous people is unclear. It may be attributed to a greater burden of modifiable risk factors ${ }^{[44]}$, linked to social determinants of health as well as the effects of colonisation, systemic racism, institutional bias and loss of traditional cultural practices $^{[3-5,45]}$.

The Table 1 summarises the available studies identified in our narrative review that specifically address cardiovascular risk factors in Indigenous populations with stroke.

\section{Management of Indigenous patients with stroke}

Stroke management has been revolutionised over recent years. Initial momentum started with multidisciplinary stroke units and development of national guidelines to enable protocol development and standardisation of care ${ }^{[58]}$. Intravenous thrombolysis with alteplase $e^{[59]}$, more recently tenecteplase $e^{[60]}$, and endovascular clot retrieval ${ }^{[6]}$ has given patients a chance of recovery from what could previously have been lifelong disability, or death. In particular, endovascular thrombectomy is now one of the most powerful treatments in medicine with a number-needed-to-treat as low as 2.6 to reduce disability from stroke ${ }^{[61]}$. Despite the strong evidence that exists in support of treatment, analysis of Indigenous patients receipt of this care is lacking. The limited data that exist demonstrate that Indigenous patients may be less likely to receive evidence-based care ${ }^{[40,42,62-64]}$.

In Australia, Kilkenny et al.$^{[40]}$ reported that out of the 33 hospitals included in the 2009 study, rates of thrombolysis were low $(<10 \%)$. Of major concern, no Indigenous patient included in the audit received intravenous thrombolysis. Additionally, Indigenous patients were less likely to receive care in a stroke unit (adjusted odds ratio of 0.53), and when their stroke was ischaemic, Indigenous patients were less likely to receive aspirin within $48 \mathrm{~h}$ or be discharged on antithrombotic medications than non-Indigenous patients. Indigenous patients with stroke were also less likely to have an allied health assessment within $48 \mathrm{~h}$ of admission. This may have contributed to the greater dependency of Indigenous patients at discharge. Tiedeman et al. ${ }^{[42]}$ reported that Indigenous patients were less likely to have in-hospital cardiac monitoring and upon discharge were less likely to be followed up by a specialist.

Similarly, in a population-based cohort study from Ontario ${ }^{[62]}$, First Nations people admitted with stroke were less likely to receive thrombolysis than other Canadians (6.3\%vs. 11.0\%), although no difference was detected when comparing assessment with neuroimaging, carotid revascularisation or referral to rehabilitation.

In research from the United States, racial disparities are evident when analysing the use of intravenous thrombolysis for treatment of ischaemic stroke ${ }^{[65-67]}$. However, most studies fail to include identification of Indigenous Peoples as a separate treatment group and largely characterise race as "non-Hispanic White" or "Black". Within the studies that specifically mention American Indigenous groups (Native American, American Indians or Pacific Islander), Indigenous Peoples are sometimes grouped with other minority groups. For example, Aparicio et al ${ }^{[68]}$ analysed the difference in treatment rates of patients presenting to primary stroke centres versus non-primary stroke centres. They performed a retrospective cohort study using data from the Nationwide Inpatient Sample (NIS) from 2004 to 2010. The NIS classifies race/ethnicity as White, Black, Hispanic, Asian/Pacific, Native American or Other. There were 304,152 patients included in the analysis, $71.5 \%$ were White, $15.0 \%$ Black, $7.9 \%$ Hispanic and $5.6 \%$ were grouped as Other (Asian/Pacific Islander, Native American or other). When they compared thrombolysis rates between groups, all racial groups compared to Whites were significantly less likely to be treated. The adjusted odds ratio (OR) for "others" vs. White at the primary stroke centres was 0.75 (CI: 0.64-0.89) and at the non- 
Table 1. Cardiovascular risk factors in Indigenous populations in the world

\begin{tabular}{|c|c|c|c|c|c|}
\hline Country/Ref. & Aim & Study design & Sample & Results & Conclusions \\
\hline \multicolumn{6}{|l|}{ United States } \\
\hline $\begin{array}{l}\text { Nakagawa et al. }{ }^{[44]} \\
\text { (2013) }\end{array}$ & $\begin{array}{l}\text { Evaluate disparities in CVD risk } \\
\text { factors among Asians and NHPI } \\
\text { compared with Whites, } \\
\text { hospitalised with IS in Hawaii }\end{array}$ & $\begin{array}{l}\text { Retrospective; single } \\
\text { tertiary centre; } 2004- \\
2010\end{array}$ & $\begin{array}{l}1921 \text { patients hospitalised } \\
\text { with ischaemic stroke. } \\
\text { (NHPI } 20 \% \text {, Asians } 53 \% \text {, } \\
\text { Whites } 24 \% \text {, and Others } \\
3 \% \text { ) }\end{array}$ & $\begin{array}{l}\text { NHPI were more likely to be younger (OR: } 0.95,95 \% \mathrm{Cl} \\
0.94-0.96 \text { ), female (OR: } 1.55,95 \% \mathrm{Cl}: 1.07-2.24 \text { ), and have } \\
\text { diabetes (OR: } 2.74,95 \% \mathrm{Cl}: 1.87-4.00 \text { ), hypertension (OR: } \\
\text { 1.98, 95\%Cl: } 1.27-3.10 \text { ), and obesity (OR: } 1.82,95 \% \mathrm{Cl} \text { : } \\
\text { 1.25-2.65) than Whites. Compared with Asians, NHPI were } \\
\text { more likely to be younger (OR: } 0.95,95 \% \mathrm{Cl}: 0.94-0.97 \text { ) } \\
\text { and have diabetes (OR: } 1.88,95 \% \mathrm{Cl}: 1.35-2.61 \text { ), previous } \\
\text { stroke or TIA (OR: } 1.57,95 \% \mathrm{Cl}: 1.09-2.25 \text { ), and obesity } \\
\text { (OR: } 6.05,95 \% \mathrm{Cl}: 4.31-8.48 \text { ) }\end{array}$ & $\begin{array}{l}\text { Disparities could be attributable to } \\
\text { biological and social determinants of } \\
\text { disease }\end{array}$ \\
\hline $\begin{array}{l}\text { Nakagawa et al. }{ }^{[46]} \\
\text { (2012) }\end{array}$ & $\begin{array}{l}\text { Evaluate disparities in CVD risk } \\
\text { factors among NHPI hospitalised } \\
\text { with ICH }\end{array}$ & $\begin{array}{l}\text { Retrospective; single } \\
\text { tertiary centre; 2004- } \\
2010\end{array}$ & $\begin{array}{l}562 \text { patients hospitalised } \\
\text { for acute ICH (Asian } 63 \% \text {, } \\
\text { NHPI } 18 \% \text {, White } 16 \% \text {, } \\
\text { other } 3 \% \text { ) }\end{array}$ & $\begin{array}{l}\text { NHPI were younger (NHPI } 55 \text { years vs. White } 66 \text { years, } P< \\
0.0001 \text { ), and had higher prevalence of diabetes (NHPI } 35 \% \\
\text { vs. White } 20 \%, P=0.01 \text { ) and history of HTN (NHPI } 77 \% \\
\text { vs. White } 64 \%, P=0.04 \text { ) than White patients }\end{array}$ & $\begin{array}{l}\mathrm{NHPI} \text { with } \mathrm{ICH} \text { are younger and have } \\
\text { greater burden of risk factors } \\
\text { compared to White patients }\end{array}$ \\
\hline $\begin{array}{l}\text { Nakagawa et al. } \\
\text { (2015) }\end{array}$ & $\begin{array}{l}\text { Compare clinical characteristics } \\
\text { between } \mathrm{NH} \text { and PI hospitalised } \\
\text { with IS }\end{array}$ & $\begin{array}{l}\text { Retrospective; single } \\
\text { tertiary centre; 2006- } \\
2012\end{array}$ & $\begin{array}{l}561 \text { patients ( } 57 \% \mathrm{NH} \text { and } \\
43 \% \mathrm{PI} \text { ) }\end{array}$ & $\begin{array}{l}\text { PI were younger ( } 59 \text { years vs. } 62 \text { years, } P=0.002) \text {, higher } \\
\text { prevalence of diabetes mellitus ( } 58 \% \text { vs. } 41 \%, P<0.0001) \\
\text { and lower prevalence of smoking ( } 14 \% \text { vs. } 21 \%, P=0.03 \text { ) } \\
\text { compared to } \mathrm{NH}\end{array}$ & $\begin{array}{l}\text { Whilst differences were seen, they } \\
\text { were not as significant as seen in othe } \\
\text { studies comparing Native Hawaiians } \\
\text { a non-Hispanic population }\end{array}$ \\
\hline $\begin{array}{l}\text { Owolabi et al. }{ }^{[37]} \\
\text { (2017) }\end{array}$ & $\begin{array}{l}\text { Compared characteristics and } \\
\text { risk factors of stroke in } I A \text { in West } \\
\text { Africa (SIREN study) } \\
\text { strokes in } A \text {. with and EA in the } \\
\text { Whited States (REGARDS study) }\end{array}$ & $\begin{array}{l}\text { SIREN is a large } \\
\text { multinational case- } \\
\text { control study in West } \\
\text { Africa. REGARDS is a } \\
\text { cohort study in the } \\
\text { United States }\end{array}$ & $\begin{array}{l}1928 \text { included, } 811 \text { were IA, } \\
452 \mathrm{AA} \text { and } 665 \mathrm{EA}\end{array}$ & $\begin{array}{l}\text { IA were younger (68) compared with } A A(73) \text { and even } \\
\text { younger than EA }(76) P<0.0001 \text {. IA were much more } \\
\text { likely to have haemorrhagic strokes than EA (IA } 27 \%, A A \\
8 \%, E A 5.4 \%, P<0.001) \text {. IA and AA had a greater } \\
\text { prevalence of hypertension, high cholesterol and diabetes } \\
\text { mellitus }\end{array}$ & $\begin{array}{l}\text { They concluded that race played a } \\
\text { major role in the predisposition of } \\
\text { vascular risk factors whilst } \\
\text { geographical location potentially } \\
\text { influenced stroke type }\end{array}$ \\
\hline
\end{tabular}

\section{Chile}

Soto et al. ${ }^{[50]} \quad$ Estimate the magnitude of the (2019) association between Mapuche ethnicity and stroke occurrence

Incident case control- 208 patients, 104 cases paired study with patients admitted with stroke hospitalised in a single matched with 104 controls centre between 2017 2018 without stroke. Within the cases, $27.9 \%$ were $32.7 \%$ of the controls

\section{Ecuador}

Del Brutto et al. ${ }^{[51]} \quad$ To assess which risk factors are (2014) vascular events (stroke and ischaemic heart disease) in natives/Mestizos living in rural coastal Ecuador

\section{Australia}

Tiedeman et al. ${ }^{[42]}$ To compare investigations and
Population-based case- $\quad 642$ residents aged $40+$ control study in a single years, with 24 cases of region; 2013 years, with 24 cases of
vascular events and 96 matched controls
No detectable difference in the association between Risk factors for stroke included obesity,

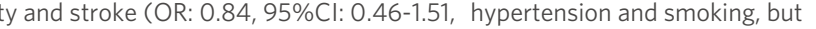
$\begin{array}{ll}P=0.55) \text {. Ethnicity was not a factor associated with stroke } & \text { Mapuch } \\ \text { when adjusted for hypertension, obesity, low } & \text { factor }\end{array}$ socioeconomic status, rurality, diabetes mellitus and smoking

The only difference detected in the cardiovascular risk factor profile was that cases undertook less physical

The authors concluded that none of activity than wontrols (OR: $28,95 \%$ Cl: 1.2-43, $P<0.0001)$ the measured risk factors were

vascular events apuche ethnicity was not a risk 
(2019) management of Indigenous and non-Indigenous patients with IS to national stroke standards

single centre; 2010-2015

Prospective cohort study; 1843 patients, $2.5 \%$

Dos Santos et al. ${ }^{[41]}$ To estimate the difference in stroke recognition, risk factors, treatment rates and outcomes between Indigenous and nonIndigenous peoples at a single centre

He et al. ${ }^{[52]}$ (2015) Compare stroke recurrence and

Kilkenny et al. ${ }^{[40]}$ Compare guideline-directed care Australian national stroke (2013) and outcomes in Indigenous and role of comoricic role of comorbidities in adverse
stroke outcomes (recurrence and death) between Indigenous and non-Indigenous Australians Australian national stroke 305 patients, $18 \%$ Indigenous, age-restricted non-Indigenous patients admitted hospitals; $2009 \quad$ from 18-64 years

2105 patients, $43.9 \%$ Indigenous

Retrospective cohort 2105 patients study; single centre;

with acute stroke
Katzenellenbogen To determine the prevalence of State-wide linked hospital 13591 cases, 5\% Indigenous et al. ${ }^{[36]}$ (2014) hospitalized stroke and coexistent and mortality data 2007conditions in Indigenous and non- 2011 Indigenous people in Western Australia

\section{Canada}

Anand et

Anand

To determine which factors, account for the variations in cardiovascular risk (determined by the INTERHEART score) in First Nations

Hu et al. ${ }^{[26]}$ (2019) To describe the cardiovascular health profile of Canadian Inut comparison to the general Canadian population
Population-based study 1302 participants, all First from 8 First Nations Nations ies, cross-

Two cross-sectional surveys (Inuit communities -HIS. $2007-$ 2008) and (general Canadian population CHMS; 2007-2009 and 2012-2013)

IHS; 2070 Inuit adults (2079 years). CHMS; 3464 Canadian adults (20-79 years). To compare results digenous patients admitted to a single centre with an IS

Indigenous patients with stroke were 15.8 years younger have a higher prevalence of ( 56.8 years vs. 72.6 years, $P<0.001$ ), and were more likely preventable disease, including those to have risk factors for stroke, including smoking $(51.2 \%$ vs. that confer a higher stroke risk $15.0 \%, P<0.001)$, diabetes mellitus ( $37.2 \%$ vs. $16.8 \%, P=$ $0.003)$ and past history of CVA or TIA ( $50.2 \%$ vs. $31.1 \%$, $=0.032)$

Indigenous patients were younger (62 years vs. 74 years), Indigenous Australians with stroke are and more likely to have diabetes (RD: 22.3\% [95\% Cl: 3\%, a decade younger and have a higher $41.7 \%]$ ), dyslipidaemia (RD: $19.4 \%$ [95\%Cl: $21 . \%, \quad$ prevalence of important, modifiable $36.7 \%]$ ), and have ever smoked (RD: $24.9 \%$ [95\%Cl: stroke risk factors

$9.5 \%, 40.3 \%])$ In multivariable analyses, adjusting for comorbidities Some of the excess risk of death 1.25, 0.88-178) and excess risk for both case fatality (OR. - following a stroke was attributable to was considerably reduced (when compared to unadjusted analyses

Smoking, diabetes mellitus and excessive alcohol consumption were greater in Indigenous patients admitte to hospital with stroke than in non-Indigenous patients

Indigenous patients with stroke had worse health outcomes eve adjusting for hospital site, age, risk factors (diabetes mellitus, smoking alcohol), stroke severity variables (speech impairment, incontinent within $72 \mathrm{~h}$ ), stroke subtype, and access to a stroke unit

Indigenous stroke survivors aged less than 70 years had of the same age mary prevention can reduce disparities in incidence and prevalence, the wider solutions lie in tackling disadvantage

Communities with greater socioeconomic advantage (greater employment, higher income and longterm marital partnerships), greater trust between community members, higher education levels and supportive cardiovascular risk factors

Inuit females had greater prevalence of heart attack (3.1\% vs. $1.8 \%$ ), stroke ( $2.2 \%$ vs. $1.0 \%)$, diabetes $(14.6 \%$ vs. between the IHS and (3.8\% vs. $24.2 \%)$, HTN (7.5\% vs. $25 \%)$ than non-Inuit females

Canadian Inuit, in comparison to the general Canadian population, have different health profiles and a greater burden of cardiovascular diseases 
non-Inuit males and females

Norway

Siri et al ${ }^{[54]}$

To assess and compare

cardiovascular risk factors and

the 10-year risk of myocard

infarction or stroke (using

NORRISK2 model)
Sami and non-Sami populations

of Northern Norway

Siri et al. ${ }^{[38]}$ (2019) To describe the changes in

cardiovascular risk factor profile and risk of myocardial infarction or stroke amongst the Sami and non-Sami population

Taiwan

Hung et al. ${ }^{[57]}$

(2016)

Comparison of demographic

details, conventional and

behavioural risk factors between

Taiwanese Aborigines and $\mathrm{H}$

Chinese patients with stroke

\section{Cross-sectional \\ 6004 participants: 5318 \\ Copulation-based survey; included (40.8\% Sami)}

2012-2014

Between the Sami and non-Sami population of Northern Norway, only minor differences were seen in the prevalence of cardiovascular risk factors

$\begin{array}{ll}\text { Cross-sectional surveys - } & 6417 \text { participants in } \\ \text { SAMINOR } 1^{[55]} ; 2003- & \text { SAMINOR 1,5956 }\end{array}$

participants in SAMINOR

Estimated 10-year risk of myocardial infarction and strok declined in all strata of sex and ethnicity over this $10-y e a r$ 2004, SAMINOR $2^{[54]}$ period $(P<0.001)$

Prospective cohort study; 433 patients identified, 302 single centre; 2007-2009 were Han Chinese (70\%) and $131 \mathrm{w}$ Aborigines (30\%)
No difference in demographic profile (age, sex, social class, Traditional cardiovascular risk factors marital status, body mass index) between groups. In both for stroke are similar but given betel groups, hypertens mass index) between groups. In both The prevalence of ischaemic heart disease, high Chinese more likely to have diabetes than Taiwanese Aborigines and less likely to have atrial fibrillation $(P=$ 0.018), consume alcohol $(P=0.046)$ and betel nuts $(P=$ 0.001 )

CVD: Cardiovascular disease; NH: Native Hawaiians; PI: Pacific Islanders; NHPI: Native Hawaiian and Pacific Islanders; IS: ischaemic stroke; OR: odds ratio; Cl: confidence interval; ICH: intracranial haemorrhage; HTN: hypertension; IA: Indigenous Africans; AA: African Americans; EA: European Americans; RD: risk difference; HIS: Inuit Health Survey; CHMS: Canadian Health Measures Survey.

primary stroke centre 0.75 (CI: 0.62-0.88), showing that 25\% fewer Asian/Pacific Islander, Native American or other received thrombolysis in comparison to Whites.

In 2014 Kimball et al. ${ }^{[64]}$ also analysed the NIS database. Their retrospective study included 477,474 patients between 2002 and 2008 with ICD-9 codes for ischemic stroke. Race was classified as White, African American, Hispanic, Asian/Pacific Islander, Native American, or Other. They did not combine Native American with Other. They determined that race was independently associated with thrombolysis (OR: 0.59; $95 \%$ CI: $0.39-0.91 ; P=0.0166)$. They also determined that, relative to Whites, Native Americans were unlikely to be treated in a high-volume stroke centre (OR: 0.73; 95\%CI: $0.65-0.83$; $P$ < 0.0001). They comment that Native Americans are more likely to live in the remote "Four Corners region of the southwest United States and rural Oklahoma". Consequently, these patients are then less likely to receive thrombolysis as they are less likely to present to a large volume stroke centre within treatment windows. 
Regarding endovascular thrombectomy, several United States-based studies have similarly grouped Indigenous Peoples with other minority groups and shown racial disparities ${ }^{[69,70]}$.

Attenello et al ${ }^{[63]}$ separated racial groups when they examined the 2008 NIS database. They reported that White, Hispanic and Asian/Pacific Islander received endovascular thrombectomy at higher rates than Black and Native Americans $(P<0.001)$. Additionally, they noted that, compared to Whites, Native American patients were less frequently admitted to hospitals that could perform thrombectomy than other racial groups $(P<0.001)$.

\section{DISCUSSION}

Within the constraints of a narrative review, stroke incidence rates appear variable between the Indigenous and non-Indigenous populations, depending on the country. From the available studies in our review, incidence rates are greater for Indigenous groups of Australia ${ }^{[1,14-16]}$, New Zealand ${ }^{[17]}$, Sweden ${ }^{[32]}$, and Israel $^{[20]}$. There are conflicting reports from the United States ${ }^{[23-26]}$ and Canada ${ }^{[27,28,30]}$ and incidence rates are either similar or lower in South America ${ }^{[31]}$, Russia $^{[33]}$ and Tibet ${ }^{[19]}$.

There is overwhelming evidence from the literature that Indigenous Peoples are affected by stroke at a younger average age, in comparison to the non-Indigenous people in the same region ${ }^{[1,14-17,40-43]}$. This not only affects the individual, due to longer time spent with disability and reduced quality of life, but also has a domino effect on their family and community. There are additional economic considerations for countries, with the indirect costs after IS estimated to be 6 times greater for adults aged $<65$ years compared with adults aged $\geq 65$ years in the United States ${ }^{[47]}$. Cardiovascular risk factors are generally more prevalent amongst the Indigenous population compared to the non-Indigenous population in Australia ${ }^{[3,40-42,52]}$, United States ${ }^{[37,44,45]}$ and Canada ${ }^{[5,26]}$ but not in Chile ${ }^{[50]}$, Ecuador ${ }^{[51]}$, Taiwan ${ }^{[57]}$ and Norway ${ }^{[4,55]}$. Drawing conclusions regarding guideline-directed treatment with intravenous thrombolysis and/or endovascular clot retrieval is problematic due to the lack of studies designed to specifically address this question. However, from the studies included in this review, there was clear evidence that Indigenous patients in Australia ${ }^{[00,42]}$, United States ${ }^{[65-70]}$ and Canada ${ }^{[62]}$ were less likely to receive treatment with thrombolysis or undergo endovascular clot retrieval in comparison to their non-Indigenous counterparts.

Similar to the general health of all populations, stroke and its outcomes are the result of the complex interactions between different factors that act at the individual, community, societal, and service levels. As shown in our hierarchical framework, human rights factors and the social determinants of health resulting from these, trigger a cascade of events leading to stroke and stroke inequities that are particularly marked in Indigenous Peoples worldwide [Figure 1]. In particular, colonisation (including the cultural and material losses associated with it), is a major indirect driver of disparities in lifestyle, biological and other risk factors for stroke in Indigenous Peoples ${ }^{[12,45]}$.

Our findings suggest that a rapid shift must occur in those countries where Indigenous patients have greater incidence rates of stroke, more prevalent comorbidities, and lesser treatment rates than non-Indigenous patients. In particular, there is an urgent need for the provision of evidence-based care to increase the opportunities for optimal health outcomes preventing stroke ${ }^{[4]}$. However, before this occurs, improvement of social infrastructure and an emphasis on the importance of culture for Indigenous People, should become the norm. The loss of traditional cultural practices, dispossession from the land, loss of connectedness, loss of Indigenous identity and the misalignment of what "health" means to Indigenous Peoples continue to underpin the foundations of the health gap. Coupled with discrimination and disadvantage (including economic, environmental and educational $)^{[5,36]}$ there are issues such as institutional racism ${ }^{[7]}$, 


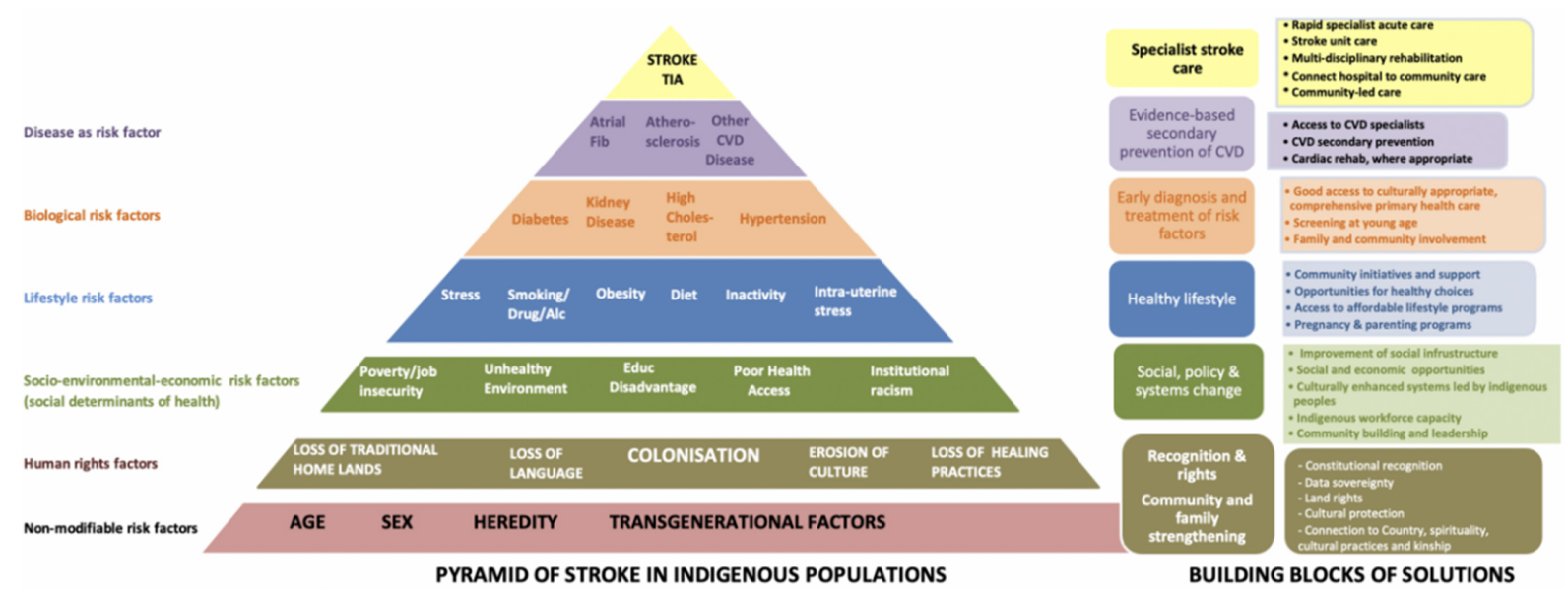

Figure 1. Hierarchical framework of stroke inequity. TIA: Transient ischaemic attack; CVD: cardiovascular disease.

communication barriers and the lack of culturally appropriate services.

Other considerations include poorer access to culturally sensitive, comprehensive primary and secondary prevention programs. Without this, there is under-diagnosis of cardiovascular risk factors and lesser treatment rates $^{[5,38]}$. This is particularly important in the younger age groups ${ }^{[36,41]}$. There are geneenvironment interactions that highlight the importance of the social environment, which should be further explored $^{[44]}$. In addition, biological differences in genetic polymorphisms and variation in drug metabolism play integral roles in the risk factor profile ${ }^{[46]}$. However, Indigenous Peoples' justified concerns surrounding the use of Indigenous biologic samples, and unresolved tensions surrounding the need for Indigenous governance and data sovereignty ${ }^{[72-74]}$ in mainstream health and medical research must be addressed before research of this kind can proceed.

Improvements in, and access to, education will give rise to improved health literacy with reinforced messages that encourage medication adherence ${ }^{[47]}$. Community-led support programs where traditional cultural values strengthen families and communities will help reduce smoking rates, alcohol intake and obesity, although these lifestyle factors are not solely Indigenous-specific issues ${ }^{[5,36,37]}$.

Transformative, innovative, population-specific public health policies should be developed to specifically target the unique challenges of health care delivery in Indigenous populations, including but not limited to regional and remote $\operatorname{areas}^{[26]}$. Issues in relation to transportation, delays in treatment, lack of access to specialists, housing and food insecurity, have specific consequences for health. A delayed hospital presentation translates to reduced treatment rates and poorer outcomes ${ }^{[75]}$. In contrast, in the context of United States, in high volume primary stroke centres, where access to stroke specialists, neurologists, neurointerventionists and neurosurgeons is greater, all patients are 3.7 times $^{[76]}$ more likely to receive thrombolysis and are more likely considered for endovascular clot retrieval. This, in turn, results in lower mortality and morbidity rates. Several United States states have adopted the "Hub and Spoke" model ${ }^{[77,78]}$ with the use of telemedicine, whereby a smaller peripheral hospital can contact a stroke specialist and gain advice on rapid treatment before transferring to the primary stroke centre. This model of care is particularly relevant for all Indigenous Peoples, in all countries, who may live in areas without access to a primary stroke centre. Additional considerations as to the reasons why Indigenous Peoples are less often treated include delayed presentation to hospital due to lack of awareness of stroke symptoms, mistrust or misunderstanding of the health care system, language barriers and resultant poor communication, low income or education 
level and the possibility of lower National Institute of Health Stroke Scale scores, differences in aetiology or contraindications to thrombolysis or endovascular thrombectomy ${ }^{[41,62,63,68,78]}$. Besides individual-level risks, institutional racism plays an important role in reduced access to specialist interventions. There is also evidence that, even when arriving to hospital in a timely manner, Indigenous Peoples wait longer in the emergency department ${ }^{[63]}$. The flow-on effects of lifelong disability related to delayed treatment, no treatment or curtailed treatment, are unacceptable.

Whilst our review did not specifically address mortality, several studies have provided evidence that Indigenous Peoples have greater mortality rates than non-Indigenous Peoples ${ }^{[11]}$. In Australia, there are multiple reports of higher stroke mortality rates in Indigenous Australians compared with nonIndigenous ${ }^{[36,52,79]}$. In New Zealand ${ }^{[80]}$, the 30-day case fatality rate for patients with IS was analysed over 2 time periods and compared. In 2000-2004 the case fatality rate was larger for Māori than Europeans, and in 2010-2014 it was greater for all ethnic groups than Europeans. In Canada ${ }^{[62]}$ similar results have shown Indigenous Peoples have a greater case fatality rate following stroke than non-Indigenous.

In Australia and the United States, greater rates of haemorrhagic stroke are reported amongst Indigenous Peoples than non-Indigenous people. It is likely that this large rate of haemorrhagic stroke is associated with greater disability and mortality, given that this type of stroke has significantly poorer outcomes than IS ${ }^{[46]}$. Thus stroke subtype, whilst influenced by the prevalence of risk factors, may also have a causal relationship with higher case fatality.

The cumulative effects of lower socioeconomic status and Indigenous identity on stroke incidence rates, risk factors and treatment, have been difficult to elucidate. Many of the referenced authors observed that the data sources do not directly record socioeconomic status ${ }^{[40,79]}$; hence, this variable could not be included in analyses. Despite this, it is well documented that lower socioeconomic status is a risk factor for cardiovascular disease ${ }^{[62]}$, and poorer access to quality health care ${ }^{[54]}$ including access to high volume stroke centres $^{[63]}$, particularly in regions where there is residential segregation ${ }^{[46]}$. Therefore, it is likely that socioeconomic status may be one of the mediators of the observed greater incidence rates of stroke and poorer outcomes in Indigenous Peoples.

A major hindrance to quality data on this topic is the lack of large samples of Indigenous Peoples ${ }^{[40,62]}$. Indigenous Peoples commonly represent a minority group in their region, and hence sample sizes are often small. This makes meaningful statistical comparisons with the non-Indigenous population difficult, as sample sizes may be underpowered. Points raised relating to this issue include the need for a greater emphasis on research questions that are driven by the communities identified needs, the Indigenous consent process, consensus for Indigenous identity procedures and reinforcing the dialogue of Indigenous governance and data sovereignty ${ }^{[1,82]}$. Gaining informed consent, which can be compounded by language barriers, cultural incompetence and insensitivity of researchers, is a difficult issue. However, suggestions for improvement lie in the involvement of healthcare workers from the selected communities before the research begins. Community views on the need of the research objective and cultural considerations should be entwined in the research question and protocol. This should not be an afterthought. Once community consultation has been sought, healthcare workers that are fluent in the regional dialect can translate materials for participants. Not only does this bolster the workforce capacity of the community, creating jobs, but it also ensures appropriate research is undertaken that meets the needs of the community and incorporates cultural considerations into the entire process, including consent. 
Cruz-Flores et al. ${ }^{[7]}$ discuss race and ethnicity and describe the reasons why race has been replaced with the term ethnicity in modern society. In their words, ethnicity describes common ancestry, history or culture and emphasises the social rather than biological characteristics. In Australia, Kilkenny et al. ${ }^{[40]}$ note that, whilst there was agreement between the auditors for recording Indigenous status, there are no available data on the accuracy of these records to determine the true number of Indigenous patients admitted to hospital with stroke. Similarly, in the United States ${ }^{[63,68]}$ the NIS remains subject to biases and recording error, as a large proportion of patients are recorded as "other". In Norway, Siri et al. ${ }^{[38]}$ comment on the difficulties experienced by the Sami population, particularly related to assimilation processes and historically unethical research leading to a reduced likelihood of disclosing ethnicity. Lastly, the impact of not recording ethnicity at all may be a reason for lack of available data. The most powerful way to ensure correct identity is with self-identification. Frontline health care workers should routinely seek information about ethnicity to avoid prejudice.

Lastly, the sovereignty of data is increasingly being recognised as an important factor in Indigenous selfdetermination. The importance of Indigenous voices speaking for the rights and interests of Indigenous Peoples - "nothing about them without them"[883] - has been missing from past conversations ${ }^{[81,82]}$. Given these data and their application are about Indigenous Peoples, it is imperative that within the protocols, consent process, interpretation of findings and translation of research, Indigenous involvement should be forefront and ownership of those data not forgotten.

The future of stroke and its effect on Indigenous Peoples has shifted from documenting the relative disadvantage of individuals and their communities to finding solutions that can be targeted for improved Indigenous stroke outcomes. This can only be achieved once Indigenous Peoples write the narrative, for example, inclusion in the design and delivery of culturally safe health care that understands their lived experience and meets their needs as Indigenous People. For millennia, Indigenous groups have known the important influence of Indigenous culture on health outcomes. Culture can act as a protection against social harms and build community resilience. Health inequities will continue unless government policies address the needs of Indigenous Peoples and societal systems change to incorporate practices/policies that are appropriate for those outside the dominant culture. To decrease the incidence of stroke, we need a rapid shift towards a strength-based approach to stroke prevention and management ${ }^{[1,36,41]}$. This includes innovative ideas and health care system redesign, led by Indigenous Peoples, to improve early recognition of stroke and the quality of, and access to, acute treatment and rehabilitation services with Indigenous health care providers. We need culturally appropriate services that support the healing process. Examples of these include Indigenous specialists, Indigenous health workers/navigators, Indigenous community health professionals, increased use of interpreters, culturally appropriate information about causality and explanation of medications, and family-focused care. Cultural safety training that teaches non-Indigenous health professionals how to interact with Indigenous Peoples would help these health professionals improve health outcomes for their Indigenous patients, while community-based rehabilitation, tele-stroke and telerehabilitation services could extend care to communities ${ }^{[5,64,71]}$.

\section{LIMITATIONS}

Limitations of this study include variation in study design, including quality, data sources and methods. Furthermore, as this was conducted as a narrative rather than systematic review, we do not provide a comprehensive overview of all available literature, which may have led to bias in reporting. 


\section{CONCLUSION}

There is now overwhelming evidence that a biomedical model alone cannot make the changes necessary for Indigenous Peoples. Many Indigenous peoples have a deep attachment to alternative paradigms of health and wellbeing that do not align with Western medicine ${ }^{[84]}$. Indigenous knowledge, beliefs and values should be practised in parallel. For example, in Australia, Aboriginal and Torres Strait Islander nations have medicine and healing practices that have sustained physical and mental health for tens of thousands of years - as have other Indigenous Peoples. These traditions have survived to the present day and are being integrated into the contemporary Australian health care system to ensure their survival into the future ${ }^{[84]}$. The "hands on" and breath-based healing practices are combined with traditional plants and balms to heal within a unique belief system that combines the spiritual, physical, mental and emotional levels of being, in the context of a spiritual world, not recognised by Western medical program ${ }^{[84]}$. Embracing these cultural considerations can only strengthen health, not dismantle it. We must move forward from viewing Indigenous health and wellbeing from a Western biomedical lens only. Failure to embrace Indigenous-led healthcare will perpetuate colonisation and its harmful legacy.

\section{DECLARATIONS}

\section{Authors' contributions}

Lead author of the manuscript, writing the abstract, introduction, methods, risk factors, management and discussion: Dos Santos A

Contributed to introduction and wrote on incidence: Balabanski AH

Made substantial contributions to the manuscript with oversight and guidance on structure and content: Katzenellenbogen JM, Thrift AG, Parsons MW

Provided cultural guidance and oversight of the manuscript: Burchill L

\section{Availability of data and materials}

Not applicable.

\section{Financial support and sponsorship}

None.

\section{Conflicts of interest}

All authors declared that there are no conflicts of interest.

\section{Ethical approval and consent to participate}

Not applicable.

\section{Consent for publication}

Not applicable.

\section{Copyright}

(c) The Author(s) 2021.

\section{REFERENCES}

1. United-Nations.org [internet]. Background - International Day of the World's Indigenous Peoples | United Nations. Available from: https://www.un.org/en/observances/Indigenous-day/background. [Last accessed on 6 Apr 2020].

2. World Health Organisation, 2020. Health Topics: Indigenous Populations. Available from: https://www.who.int/topics/health_services_indigenous/en/. [Last accessed on 6 Apr 2021].

3. Gracey M, King M. Indigenous health part 1: determinants and disease patterns. Lancet 2009;374:65-75. DOI PubMed

4. Paradies Y. Colonisation, racism and Indigenous health. Journal of Population Research 2016;33:83-96. DOI

5. Anand SS, Abonyi S, Arbour L, et al. Explaining the variability in cardiovascular risk factors among First Nations communities in Canada: a population-based study. Lancet Planet Health 2019;3:e511-e20. DOI PubMed 
6. King M, Smith A, Gracey M. Indigenous health part 2: the underlying causes of the health gap. Lancet 2009;374:76-85. DOI PubMed

7. Feigin VL, Norrving B, Mensah GA. Global Burden of Stroke. Circulation Research 2017;120:439-48. DOI PubMed

8. Feigin VL, Forouzanfar MH, Krishnamurthi R, et al. Global and regional burden of stroke during 1990-2010: findings from the Global Burden of Disease Study 2010. Lancet 2014;383:245-54. DOI PubMed PMC

9. Feigin VL, Lawes CM, Bennett DA, Barker-Collo SL, Parag V. Worldwide stroke incidence and early case fatality reported in 56 population-based studies: a systematic review. Lancet Neurol 2009;8:355-69. DOI PubMed

10. Strong K, Mathers C, Bonita R. Preventing stroke: saving lives around the world. Lancet Neurol 2007;6:182-7. DOI PubMed

11. Balabanski AH, Newbury J, Leyden JM, et al. Excess stroke incidence in young Aboriginal people in South Australia: 946 pooled results from two population-based studies. Int J Stroke 2018;13:811-14. DOI PubMed

12. Anderson I, Robson B, Connolly M, et al. Indigenous and tribal peoples' health (The Lancet-Lowitja Institute Global Collaboration): a population study. Lancet 2016;388:131-57. DOI PubMed

13. Ferrari R. Writing narrative style literature review. Medical Writing 2015;24(4):230-5. DOI

14. Katzenellenbogen JM, Vos T, Somerford P, Begg S, Semmens JB, Codde JP. Burden of stroke in Indigenous Western Australians: a study using data linkage. Stroke 2011;42:1515-21. DOI PubMed

15. Balabanski AH, Goldsmith K, Giarola B, et al. Stroke incidence and subtypes in Aboriginal people in remote Australia: a healthcare network population-based study. BMJ Open 2020;10:e03953. DOI PubMed PMC

16. You J, Condon JR, Zhao Y, Guthridge SL. Stroke incidence and case-fatality among Indigenous and non-Indigenous populations in the Northern Territory of Australia, 1999-2011. Int J Stroke 2015;10:716-22. DOI PubMed

17. Feigin VL, Krishnamurthi RV, Barker-Collo S, et al; ARCOS IV Group. 30-year trends in stroke rates and outcome in Auckland, New Zealand (1981-2012): A Multi-Ethnic Population-Based Series of Studies. PLoS One 2015;10:e0134609. DOI PubMed PMC

18. Waloki M, Roseveare C, Tikolevu L, Ram S, Bissell K. Stroke rehabilitation in Fiji: are patients receiving services? Public Health Action 2014;4:150-4. DOI PubMed PMC

19. Zhao Y, Yao Z, D’Souza W, et al. An epidemiological survey of stroke in Lhasa, Tibet, China. Strok;41:2739-43. DOI PubMed

20. Zimhony N, Abu-Salameh I, Sagy I, et al. Increase in ischemic stroke incident hospitalizations among Bedouin Arabs during ramadan month. J Am Heart Assoc 2018;7:e008018. DOI PubMed PMC

21. Zhang MY, Galloway KJ, Welty OT, et al. Incidence and risk factors for stroke in American Indians: The Strong Heart Study. Circulation 2008;118:1577-84. DOI PubMed PMC

22. Harris R, Nelson LA, Muller C, Buchwald D. Stroke in American Indians and Alaska Natives: A Systematic Review. Am J Public Health 2015;105:e16-e26. DOI PubMed PMC

23. Muller CJ, Alonso A, Forster J, et al. Stroke incidence and survival in American Indians, Blacks, and Whites: The Strong Heart Study and atherosclerosis risk in Communities Study. J Am Heart Assoc 2019;8:e010229. DOI PubMed PMC

24. Boden-Albala B, Allen J, Roberts ET, Bulkow L, Trimble B. Ascertainment of Alaska Native Stroke Incidence, 2005-2009: Lessons for Assessing the Global Burden of Stroke. J Stroke Cerebrovasc Dis 2017;26:2019-26. DOI PubMed

25. Sacco RL, Boden-Albala B, Gan R, et al. Stroke incidence among white, black, and Hispanic residents of an urban community: the Northern Manhattan Stroke Study. Am J Epidemiol 1998;147:259-68. DOI PubMed

26. Hu XF, Singh K, Kenny TA, Chan HM. Prevalence of heart attack and stroke and associated risk factors among Inuit in Canada: A comparison with the general Canadian population. Int J Hyg Environ Health 2019;222:319-26. DOI PubMed

27. Martens PJ, Bartlett JG, Prior HJ, et al. What is the comparative health status and associated risk factors for the Métis? BMC Public Health 2011;11:814. DOI PubMed PMC

28. Saposnik G, Brutto OHD; Iberoamerican Society of Cerebrovascular Diseases. Stroke in South America: a systematic review of incidence, prevalence, and stroke subtypes. Stroke 2003;34:2103-7. DOI PubMed

29. United Nations Statistics Division. United Nations 2020. Available from: https://unstats.un.org/unsd/demographicsocial/products/dyb/index.cshtml. [Last accessed on 6 Apr 2021].

30. Heckmann JG, Duran JC, Galeoto J. The incidence of neurological disorders in tropical South America. Experience in the Bolivian lowlands. Fortschr Neurol Psychiatr 1997;65:291-6. DOI PubMed

31. Mienna C, Axelsson P. Somatic health in the Indigenous Sami population - a systematic review. Int J Circumpolar Health 2019;78:1638195. DOI PubMed PMC

32. Sjölander P, Hassler S, Janlert U. Stroke and acute myocardial infarction in the Swedish Sami population: Incidence and mortality in relation to income and level of education. Scand J Public Health 2008;36:84-91. DOI PubMed

33. Chugunova SA, Nikolaeva TY. The ethnic differences of stroke in Yakutia. Int J Circumpolar Health 2013:72. DOI PubMed PMC

34. World Health Organisation. Cardiovascular disease. Available from: https://www.who.int/cardiovascular_diseases/resources/atlas/en/. [Last accessed on 6 Apr 2021].

35. Harris R, Nelson LA, Muller C, Buchwald D. Stroke in American Indians and Alaska natives: a systematic review. Am J Public Health 2015;105:e16-26. DOI PubMed PMC

36. Katzenellenbogen JM, Knuiman MW, Sanfilippo FM, Hobbs MST, Thompson SC. Prevalence of stroke and coexistent conditions: disparities between Indigenous and non-Indigenous Western Australians. Int J Stroke 2014;9:61-8. DOI PubMed

37. Owolabi M, Sarfo F, Howard VJ, et al; SIREN-REGARDS Collaboration (Stroke Investigative Research and Educational NetworkReasons for Geographic and Racial Differences in Stroke). Stroke in Indigenous Africans, African Americans and European Americans. Interplay of racial and geographic factors. Stroke 2017;48:1169-75. DOI PubMed PMC

38. Siri SR, Eliassen BM, Jacobsen BK, et al. Changes in conventional cardiovascular risk factors and the estimated 10-year risk of acute myocardial infarction or cerebral stroke in Sami and non-Sami populations in two population-based cross-sectional surveys: the 
SAMINOR Study. BMJ Open 2019;9:e028939. DOI PubMed PMC

39. Sacco RL, Benjamin EJ, Broderick JP, et al. Risk Factors. Stroke 1997;28:1507-17. DOI PubMed

40. Kilkenny M, Harris D, Ritchie E, Price C, Cadilhac D. Hospital management and outcomes of stroke in Indigenous Australians: evidence from the 2009 Acute Care National Stroke Audit. Int J Stroke 2013;8:164-171. DOI PubMed

41. Dos Santos A, Mohr K, Jude M, et al. A prospective analysis of stroke recognition, stroke risk factors, thrombolysis rates and outcomes in Indigenous Australians from a large rural referral hospital. Intern Med J 2020. DOI PubMed

42. Tiedeman C, Suthers B, Julien B, Hackett A, Oakley P. Management of stroke in the Australian Indigenous population: From hospitals to communities. Intern Med J 2019;49:962-8. DOI PubMed

43. Gardiner FW, Bishop L, Dos Santos A, et al. Aeromedical retrieval for stroke in Australia. Cerebrovasc Dis 2020;49:334-40. DOI PubMed

44. Nakagawa K, Koenig MA, Asai SM, Chang CW, Seto TB. Disparities among Asians and Native Hawaiians and Pacific Islanders with ischemic stroke. Neurology 2013;80:839-43. DOI PubMed PMC

45. Churchwell K, Elkind M, Benjamin R, Carson A, Change E, Lawrence W. Call to action: Structural Racism as a fundamental driver of health disparities: A presidential advisory from the American Heart Association. Circulation 2020;142:454-68. DOI PubMed

46. Nakagawa K, Koenig MA, Seto TB, Asai SM, Chang CW. Racial Disparities among Native Hawaiians and Pacific Islanders with intracerebral hemorrhage. Neurology 2012;79:675-80. DOI PubMed PMC

47. Nakagawa K, MacDonald PR, Asai SM. Stroke Disparities: Disaggregating Native Hawaiians from other Pacific Islanders. Ethn Dis 2015;25:157-61. PubMed PMC

48. Akpalu A, Sarfo FS, Ovbiagele B, et al. Phenotyping Stroke in Sub-Saharan Africa: Stroke Investigative Research and Education Network (SIREN) Phenomics Protocol. Neuroepidemiology 2015;45:73-82. DOI PubMed PMC

49. Howard VJ, Cushman M, Pulley L, et al. The reasons for geographic and racial differences in stroke study: objectives and design. Neuroepidemiology 2005;25:135-43. DOI PubMed

50. Soto A, Morales G, Provoste R, et al. Association between Mapuche Ethnicity and Stroke: A Case-Control Study. J Stroke Cerebrovasc Dis 2019;28:1311-6. DOI PubMed

51. Del Brutto OH, Mera RM, Montalvan M, et al. Cardiovascular health status and metabolic syndrome in Ecuadorian Natives/Mestizos aged 40 years or more with and without stroke and ischaemic heart disease - An Atahualpa Project Case-Control Nested Study. $J$ Stroke Cerebrovasc Dis 2014;23:643-8. DOI PubMed

52. He VY, Condon JR, You J, Zhoa Y, Burrow JN. Adverse outcome after incident stroke hospitalisation for Indigenous and nonIndigenous Australians in the Northern Territory. Int J Stroke 2015;10:89-95. DOI PubMed

53. McGorrian C, Yusuf S, Islam S, et al. Estimating modifiable coronary heart disease risk in multiple regions of the world: the INTERHEART Modifiable Risk Score. Eur Heart J 2011;32:581-89. DOI PubMed

54. Siri SRA, Braaten T, Jacobsen BK, Melhus M, Eliassen BM. Distribution of risk factors for cardiovascular disease and the estimated 10 -year risk of acute myocardial infarction or cerebral stroke in Sami and non-Sami populations: The SAMINOR-2 Clinical survey. Scand J Public Health 2018;46:638-46. DOI PubMed PMC

55. Nystad T, Utsi E, Selmer R, et al. Distribution of apoB/apoA-1 ratio and blood lipids in Sami, Kven and Norwegian populations: the SAMINOR study. Int J Circumpolar Health 2008;67:67-81. PubMed

56. Selmer R, Igland J, Ariansen I, et al. NORRISK 2: A Norwegian risk model for acute cerebral stroke and myocardial infarction. Eur J Prev Cardiol 2017;24:773-82. DOI PubMed

57. Hung KH, Liou KC, Hsu KN, Hu C. Disparities in Ischaemic Stroke Subtypes and Risk Factors between Taiwanese Aborigines and Han Chinese in Taitung, Taiwan. Int J Gerontol 2016;10:17-21. DOI

58. Langhorne P, Williams BO, Gilchrist W, Howie K. Do stroke units save lives? Lancet 1993;342:395-8. DOI PubMed

59. Emberson J, Lees KR, Lyden P, et al. Effect of treatment delay, age, and stroke severity on the effects of intravenous thrombolysis with alteplase for acute ischaemic stroke: a meta-analysis of individual patient data from randomised trials. Lancet 2014;384:1929-35. DOI PubMed PMC

60. Parsons M, Spratt N, Bivard A, et al. A randomised trial of tenecteplase versus alteplase for acute ischemic stroke. $N$ Engl J Med 2012;366:1099-107. DOI PubMed

61. Goyal M, Menon BK, Zwam WH, et al. Endovascular thrombectomy after large-vessel ischaemic stroke: a meta-analysis of individual patient data from five randomised trials. Lancet 2016;387:1723-31. DOI PubMed

62. Kapral MK, Shah BR, Green ME, et al. Hospital admission for stroke or transient ischemic attack among First Nations people with diabetes in Ontario: a population-based cohort study. CMAJ Open 2020;8:156-62. DOI PubMed PMC

63. Attenello FJ, Adamczyk P, Wen G, et al. Racial and socioeconomic disparities in access to mechanical revascularisation procedures for acute ischemic stroke. J Stroke Cerebrovasc Dis 2014;23:327-34. DOI PubMed PMC

64. Kimball M, Neal D, Waters M, Hoh BL. Race and income disparities in ischemic stroke care: Nationwide inpatient sample database, 2002 to 2008. J Stroke Cerebrovasc Dis 2014;23:17-24. DOI PubMed

65. Hsia AW, Edwards DF, Morgenstern LB, et al. Racial disparities in tissue plasminogen activator treatment rate for stroke. A Population-Based Study. Stroke 2011;42:2217-21. DOI PubMed PMC

66. Reed SD, Cramer SC, Blough DK, Meyer K, Jarvik JG. Treatment with tissue plasminogen activator and inpatient mortality rates for patients with ischaemic stroke treated in community hospitals. Stroke 2001;32:1832-40. DOI PubMed

67. Johnson SC, Fung LH, Gillum LA, et al. Utilisation of intravenous tissue-type plasminogen activator for ischemic stroke at academic medical centers: the influence of ethnicity: editorial comment: it is time to implement stroke practice improvement programs and prevent the racial disparity in stroke care. Stroke 2001;32:1061-8. DOI PubMed 
68. Aparicio HJ, Carr BG, Kasner SE, et al. Racial disparities in intravenous recombinant tissue plasminogen activator use persist at primary stroke centers. JAHA 2015;4:e01877. DOI PubMed PMC

69. Brinjikji W, Rabinstein AA, McDonald JS, Cloft HJ. Socioeconomic disparities in the utilisation of mechanical thrombectomy for acute ischemic stroke in US hospitals. AJNR Am J Neuroradiol 2014;35:553-6. DOI PubMed PMC

70. Brinjikji W, Rabinstein AA, Cloft HJ. Socioeconomic disparities in the utilisation of mechanical thrombectomy for acute ischemic stroke. J Stroke Cerebrovasc Dis 2014;23:979-84. DOI PubMed

71. Blacker D, Armstrong E. Indigenous stroke care: differences, challenges and a need for change. Intern Med J 2019;49:945-7. DOI PubMed

72. Dalton R. Tribe blasts 'exploitation' of blood samples. Nature 2002;420:111. DOI PubMed

73. Mello MM, Wolf LE. The Havasupai Indian Tribe Case - Lessons for Research Involving Stored Biologic Samples. NEJM 2010;363:204-7. DOI PubMed

74. Ortiz-Prado E, Simbaña-Rivera K, Gómez-Barreno L, et al. Potential research ethics violations against an indigenous tribe in Ecuador: a mixed methods approach. BMC Med Ethics 2020;21:100. DOI PubMed PMC

75. Emberson J, Lees K, Lyden P, Blackwell L, Albers G. Effect of treatment delay, age, and stroke severity on the effects of intravenous thrombolysis with alteplase for acute ischaemic stroke: a meta-analysis of individual patient data from randomised trials. Lancet 2014;384:1929-35. DOI PubMed PMC

76. Cruz-Flores S, Rabinstein A, Biller J, et al. Racial-ethnic disparities in stroke care: The American experience: A statement for healthcare professionals from the American Heart Association / American Stroke Association. Stroke 2011;42:2091-116. DOI PubMed

77. Cramer SC, Stradling D, Brown DM, et al. Organization of a United States county system for comprehensive acute stroke care. Stroke 2012;43:1089-93. DOI PubMed PMC

78. Lazaridis C, Desantis SM, Jauch EC, Adams RJ. Telestroke in South Carolina. J Stroke Cerebrovasc Dis 2013;22:946-50. DOI PubMed

79. Zhao Y, Condon J, You J, Guthridge S, He V. Assessing improvements in survival for stroke patients in the Northern Territory 19922013: a marginal structural analysis. Aust Health Rev 2015;39:437-43. DOI PubMed

80. Sandiford P, Selak V, Ghafel M. Are ethnic inequalities in 30-day ischaemic stroke survival emerging as treatment becomes more effective? N Z Med J 2016;129:8-14. PubMed

81. In: Kukutai T, Taylor J, editors. . Indigenous data sovereignty: towards an agenda. Canberra: Australian National University; 2016.

82. Carroll, SR, Garba, I, Figueroa-Rodríguez, OL, et al. The CARE Principles for Indigenous Data Governance. Data Science Journal 2020;19:43. DOI

83. Potvin L. No research about "them" without "them": CJPH policy with regard to publication of health research on First Nations, Inuit, Métis and Indigenous Peoples. Can J Public Health 2020;111:818-21.

84. NPY Women's Council Aboriginal Corporation. Traditional Healers of Central Australia: Ngangkari. Australia: Magabala Books; 2013. 